\title{
LA-UR-15-29563
}

Approved for public release; distribution is unlimited.

Title: $\quad$ Performance Characterization of the Production Facility Prototype Helium Flow System

Author(s): $\quad$ Woloshun, Keith Albert

Dale, Gregory E.

Dalmas, Dale Allen

Romero, Frank Patrick

Intended for: $\quad$ Project milestone report

Issued: $\quad$ 2015-12-16 
Disclaimer:

Los Alamos National Laboratory, an affirmative action/equal opportunity employer,is operated by the Los Alamos National Security, LLC for the National NuclearSecurity Administration of the U.S. Department of Energy under contract DE-AC52-06NA25396. By approving this article, the publisher recognizes that the U.S. Government retains nonexclusive, royalty-free license to publish or reproduce the published form of this contribution, or to allow others to do so, for U.S. Government purposes. Los Alamos National Laboratory requests that the publisher identify this article as work performed under the auspices of the U.S. Departmentof Energy. Los Alamos National Laboratory strongly supports academic freedom and a researcher's right to publish; as an institution, however, the Laboratory does not endorse the viewpoint of a publication or guarantee its technical correctness. 


\section{Performance Characterization of the Production Facility Prototype Helium Flow System}

$10 / 30 / 2015$

Keith Woloshun, Greg Dale, Dale Dalmas, Frank Romero

Introduction

Note: This is a re-issue of an earlier report, expanded to include a section on system performance measurements.

The roots blower in use at ANL for in-beam experiments and also at LANL for flow tests was sized for 12 $\mathrm{mm}$ diameter disks and significantly less beam heating. Currently, the disks are $29 \mathrm{~mm}$ in diameter, with a $12 \mathrm{~mm}$ FWHM Gaussian beam spot at $42 \mathrm{MeV}$ and $2.86 \mu \mathrm{A}$ on each side of the target, $5.72 \mu \mathrm{A}$ total. The target design itself is reported elsewhere. With the increased beam heating, the helium flow requirement increased so that a larger blower was need for a mass flow rate of $400 \mathrm{~g} / \mathrm{s}$ at $2.76 \mathrm{MPa}$ (400 psig). An Aerzen GM 12.4 blower was selected, and is currently being installed at the LANL facility for target and component flow testing. This report describes this blower/motor/pressure vessel package and the status of the facility preparations.

Blower performance (mass flow rate as a function of loop pressure drop) was measured at 4 blower speeds. Results are reported below.

\section{Blower Selection}

The blower currently being used for the accelerator experiments at ANL and the flow visualization loop at LANL is a Tuthill 3206 PDplus. At $2.07 \mathrm{MPa}$ (300 psi) and, we are limited to $100 \mathrm{~g} / \mathrm{s}$ with about 138 $\mathrm{kPa}(20 \mathrm{psi}$ ) head. In order to achieve the heat transfer requirement of the new target, we need $400 \mathrm{~g} / \mathrm{s}$ at $2.76 \mathrm{MPa}$ (400 psig) as stated above. Tuthill has no blower that can achieve this. Aerzen offered 2 blower options, the performance of which is summarized in Figure 1. The GM 12.4 was chosen because it is physically smaller, fitting into a smaller pressure vessel. The $180 \mathrm{icfm}$ in the $3 \mathrm{rd}$ column corresponds to $400 \mathrm{~g} / \mathrm{s}$, at blower speed $1737 \mathrm{rpm}$. Blower displacement is $0.14 \mathrm{ft}^{3} / \mathrm{rev}$. The drive motor is a $30 \mathrm{hp}$ WEG with maximum speed $1800 \mathrm{rpm}$.

\section{Pressure Vessel}

The motor and blower are mounted inside a pressure vessel rated for the $2.76 \mathrm{MPa}$. The vessel is designed to ASME BPVC. Appendix A below shows the code calculations for the pressure vessel, as well as the calculations for the loop piping and the pressure rating of the instruments. The vessel fabricated by AA Tanks. AA Tanks makes their own drawings from LANL drawings and requirements. They then make their own ASME code validation calculations, fabricate the vessel, and pressure test to ASME required load (1.3 times design pressure). 
As with the earlier designs, the pressure vessel made of essentially 2 parts: A bell that rides on a rail to expose the blower and motor inside, and a fixed flange with all the penetrations for power, instrumentation, and helium inlet and outlet.

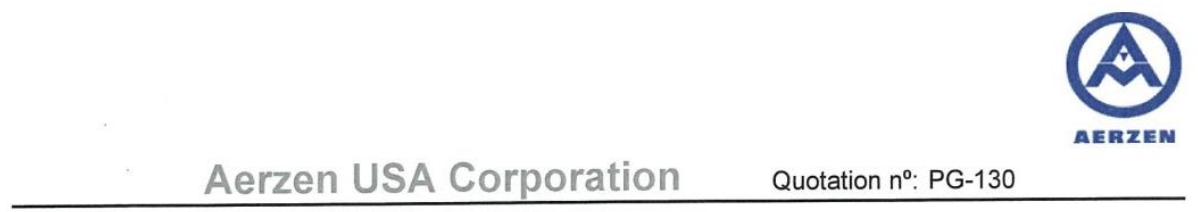
$09 / 26 / 2013$

\section{Aerzen Rotary Lobe Blower}

\section{Performance data:}

medium

operating case

MW

$\mathrm{K}=\mathrm{Cp} / \mathrm{Cv}$

volumetric flow at intake conditions volumetric flow at standard conditions volumetric flow at standard conditions specific weight at intake conditions intake pressure (absolute) discharge pressure (absolute) differential pressure intake temperature discharge temperature blower speed motor speed power required at blower shaft motor rating

\section{Tolerances:}

for volume handled at intake conditions for power consumption at blower shaft

Machine noise:

sound pressure level without hood approx. sound pressure level with hood approx.
GM 13.6 GM 13.6 GM 12.4 GM 12.4

\begin{tabular}{|c|c|c|c|c|}
\hline & Helium & Helium & Helium & Helium \\
\hline \multirow[b]{2}{*}{$\mathrm{lb} / \mathrm{lbM}$} & Given & Current dP & Given & Current dP \\
\hline & 4.00 & 4.00 & 4.00 & 4.00 \\
\hline.. & 1.660 & 1.660 & 1.660 & 1.660 \\
\hline icfm & 180 & 150 & 180 & 150 \\
\hline \multirow{2}{*}{$\begin{array}{r}\text { MMscfd } \\
\text { scfm }\end{array}$} & 7.225 & 6.021 & 7.225 & 6.021 \\
\hline & 5,017 & 4,181 & 5,017 & 4,181 \\
\hline $\mathrm{lb} / \mathrm{ft}^{3}$ & 0.294 & 0.294 & 0.294 & 0.294 \\
\hline psia & 414.5 & 414.50 & 414.50 & 414.50 \\
\hline psia & 436.3 & 432.50 & 436.25 & 432.50 \\
\hline \multirow[t]{2}{*}{ psi } & 21.8 & 18.0 & 21.8 & 18.0 \\
\hline & 66.2 & 66.2 & 66.2 & 66.2 \\
\hline${ }^{\circ} \mathrm{F}$ & 83 & 81 & 81 & 79 \\
\hline \multirow{2}{*}{$\begin{array}{l}\mathrm{rpm} \\
\mathrm{rpm}\end{array}$} & 1,019 & 877 & 1,737 & 1,482 \\
\hline & 1,019 & 877 & 1,737 & 1,482 \\
\hline \multirow[t]{2}{*}{ BHP } & 28 & 20 & 24 & 18 \\
\hline & 40 & 25 & 30 & 20 \\
\hline
\end{tabular}

$\pm 5 \%$

$\pm 5 \%$

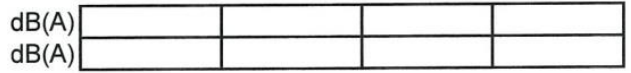

Figure 1. Performance Table for the Aerzen blowers.

\section{Blower/Motor/Pressure Vessel Assembly}

The assembly is best described with the drawing and photographs in Figures 2 through 5. Not shown, but since installed, is a sound-proofing box procured from Industrial Noise Control to reduce the blower noise from the $90 \mathrm{~dB}$ range to closer to $70 \mathrm{~dB}$. 


\section{Additional Loop Components}

Blower heating of the helium will be removed with a plate type heat exchanger from GEA, part number FP10X20L-90. This is sized to keep the helium pressure drop to less than $1 \mathrm{psi}$ in the exchanger. This is shown in Figure 6 along with connected helium and water piping and some instruments.

Helium flow rate will be measured using a turbine type meter, Omega PN FTB-939. Also installed for flow measurement is a vortex flow meter from Sierra Instruments. This flow meter has been used unsuccessfully on an earlier loop but has been reinstalled here for more cross-comparison with the turbine type under different conditions.

Temperature is measured at numerous locations around the loop with Type $\mathrm{K}$ thermocouples. Pressure is measured by gages and transducers acquired from Omega. A motor driven ball valve will be used to characterize the blower output curve mass flow rate vs pressure drop, as a function of motor speed. Although the blower is intended to run at full speed in the plant, this test facility has the motor on a variable frequency drive for flexibility and adaptability to a variety of test and experiment conditions. A P\&ID is shown in Figure 7.

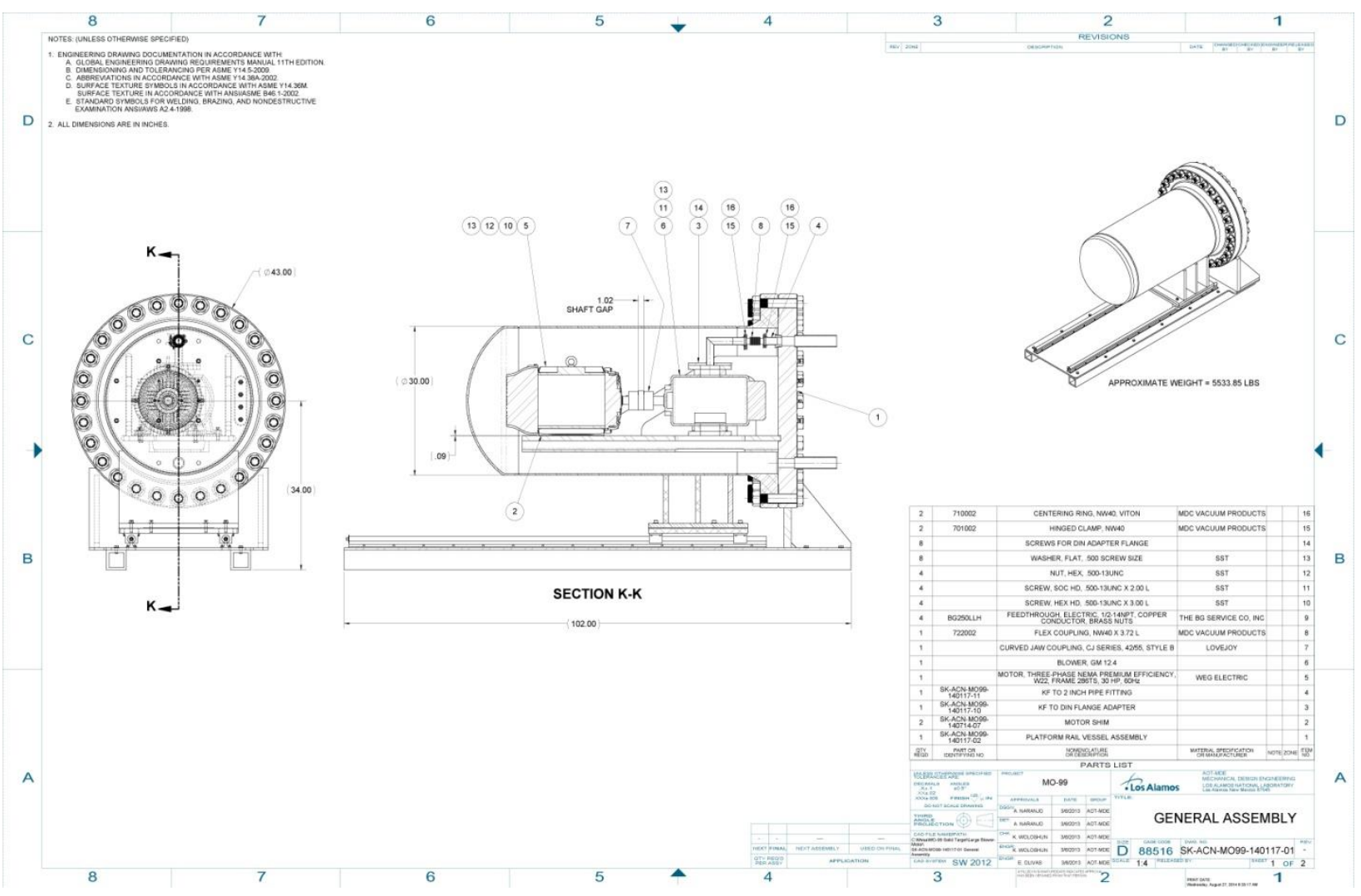

Figure 2. Drawing of the blower and motor in the pressure vessel, indicating overall dimensions. 


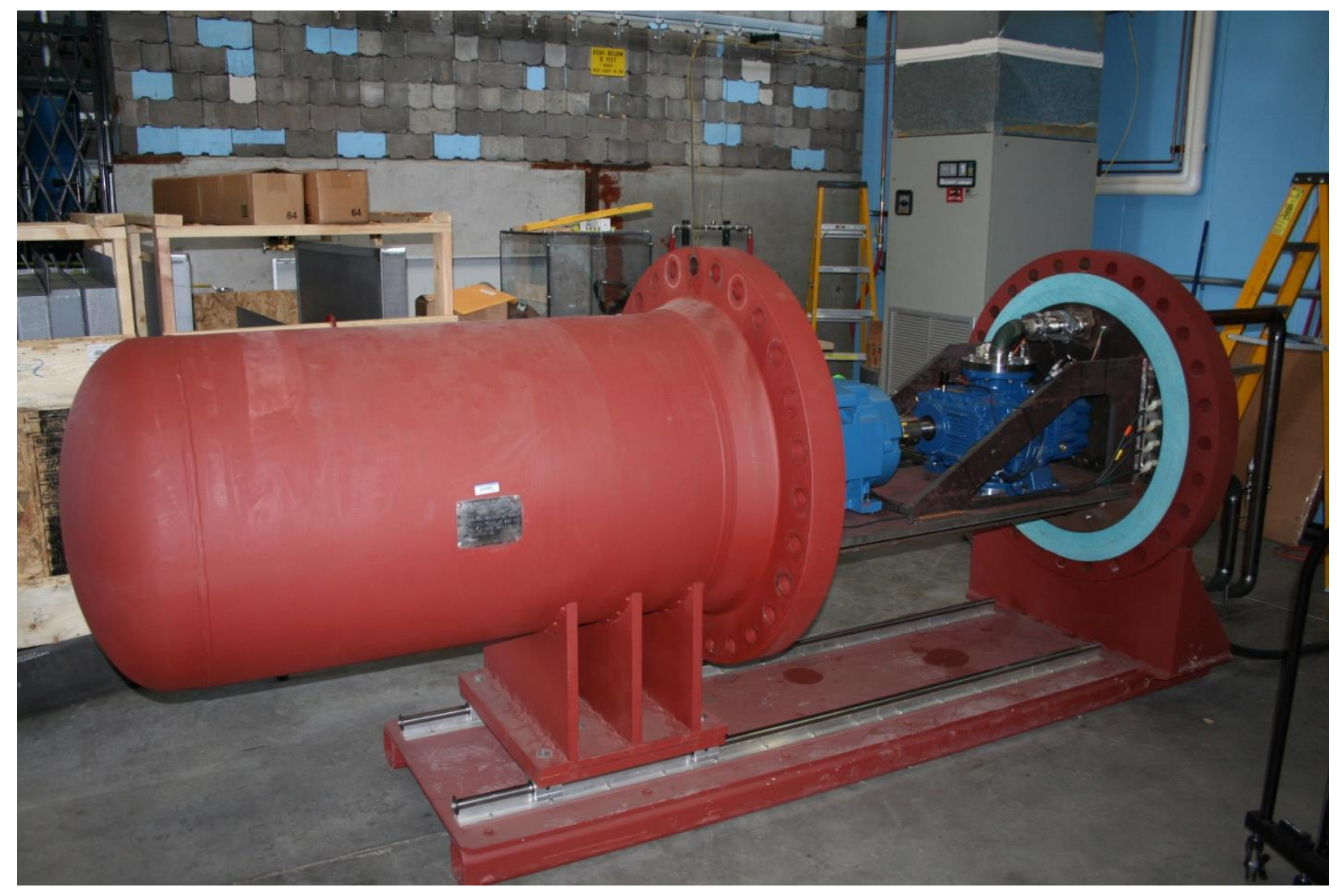

Figure 3. Vessel open, showing blower and motor. 


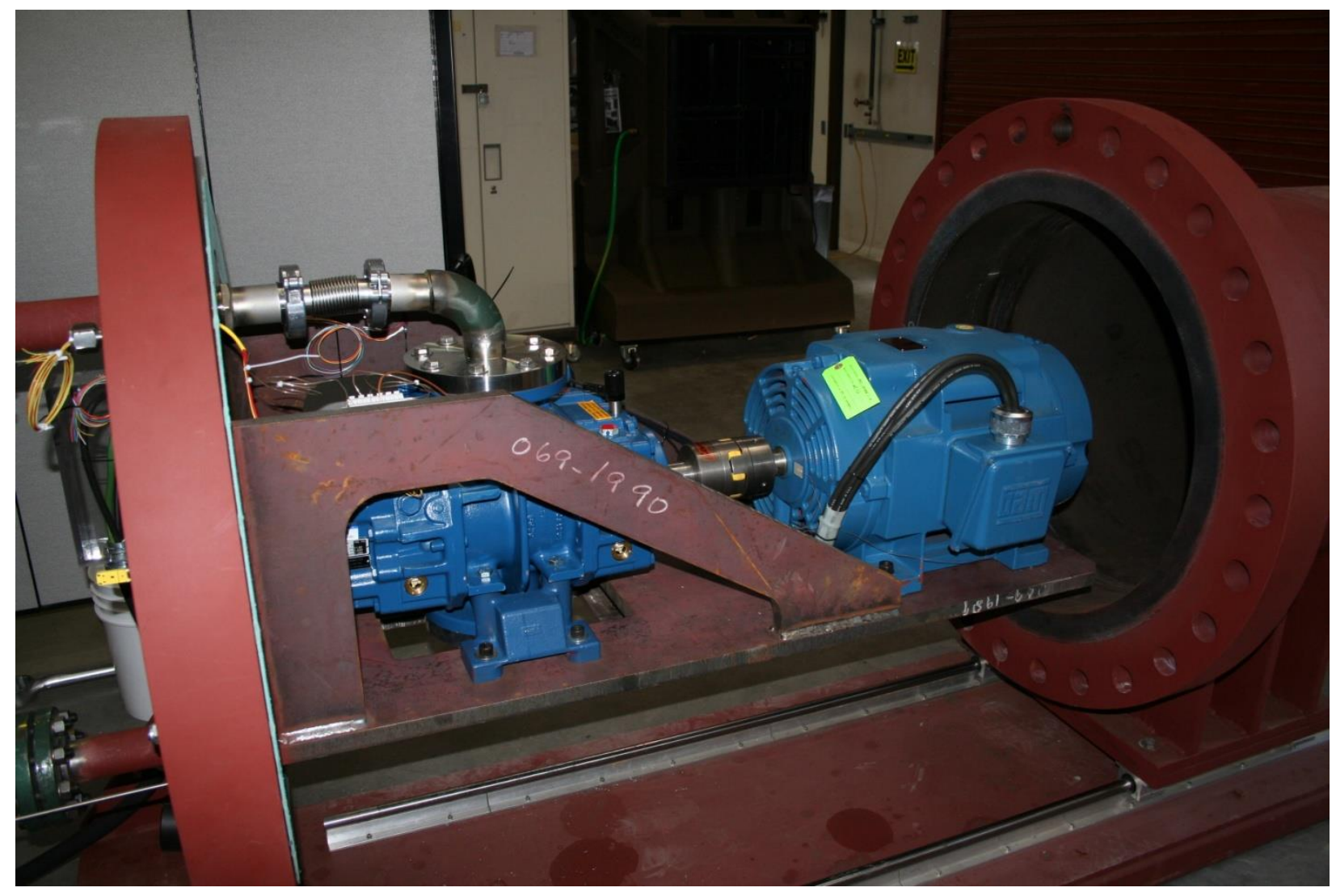

Figure 4. Close-up view of the blower, on the left, with motor. Motor is wired and blower exit piping is installed. (top left). 


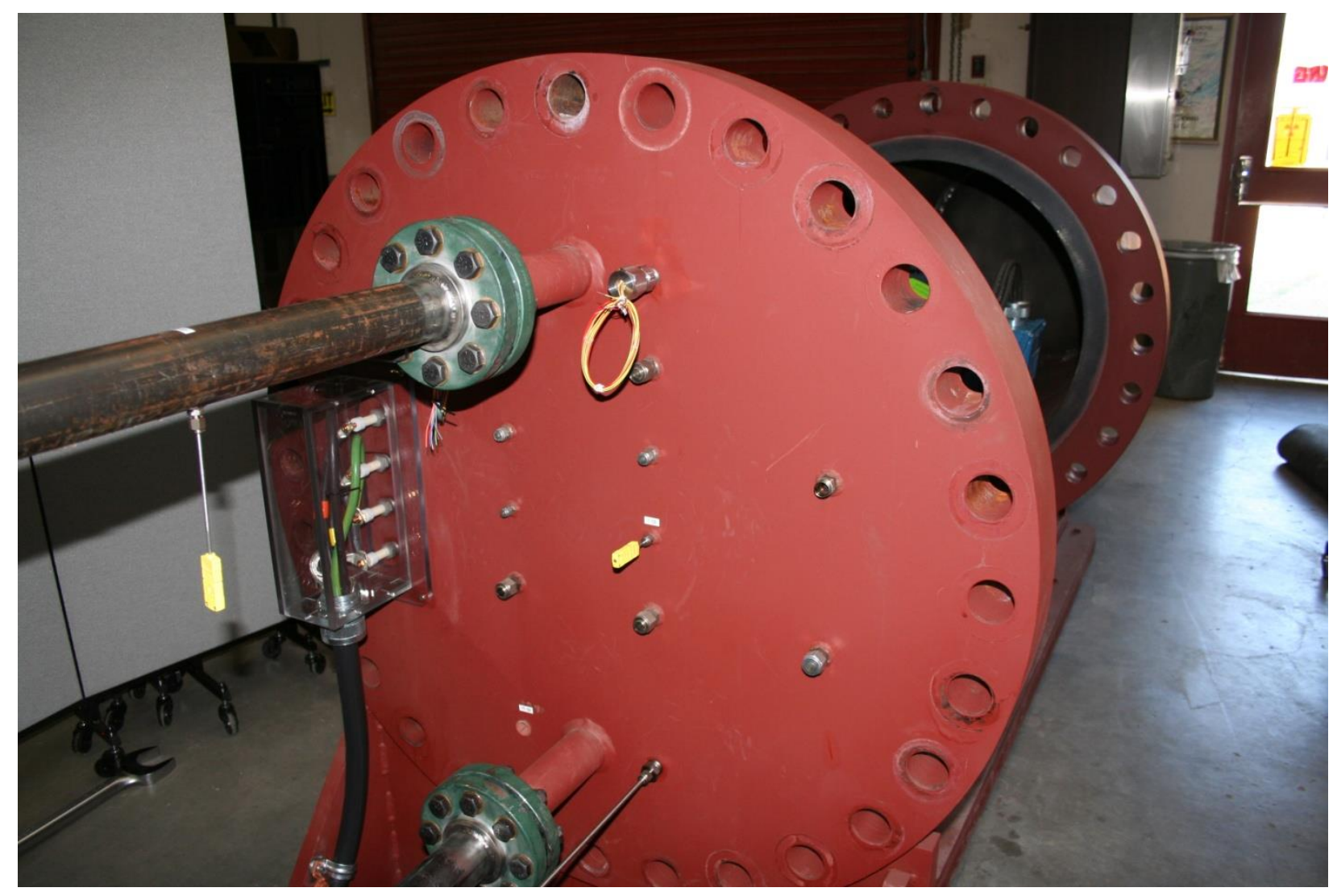

Figure 5. Fixed flange. Motor power inlet feed-throughs at center left, helium discharge pipe at the top, and return helium pipe at the bottom. Some instruments for temperature and accelerometers installed. 


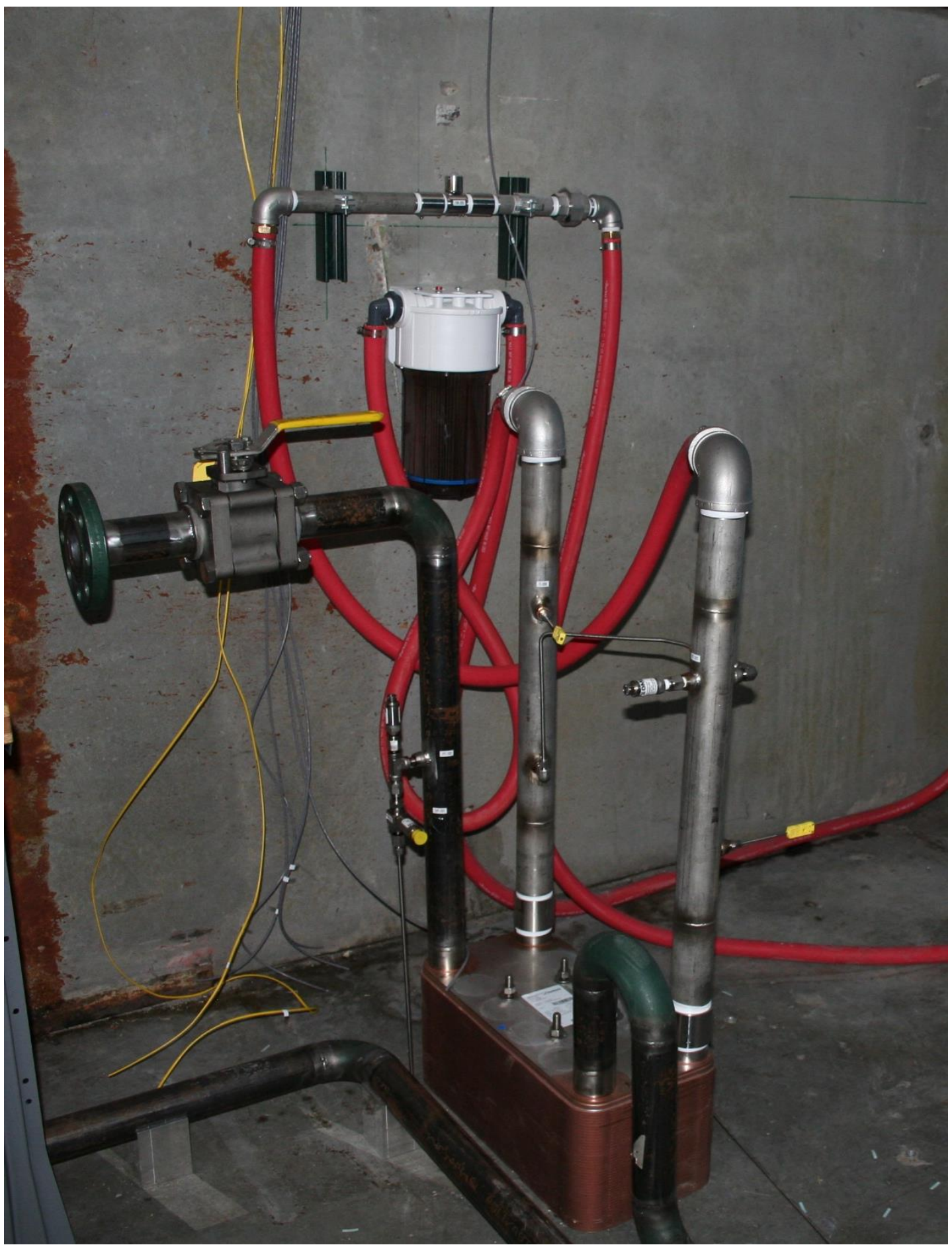

Figure 6. Heat exchanger (bottom of photo) along with piping and instruments. A water filter is mounted on the wall near the top. 


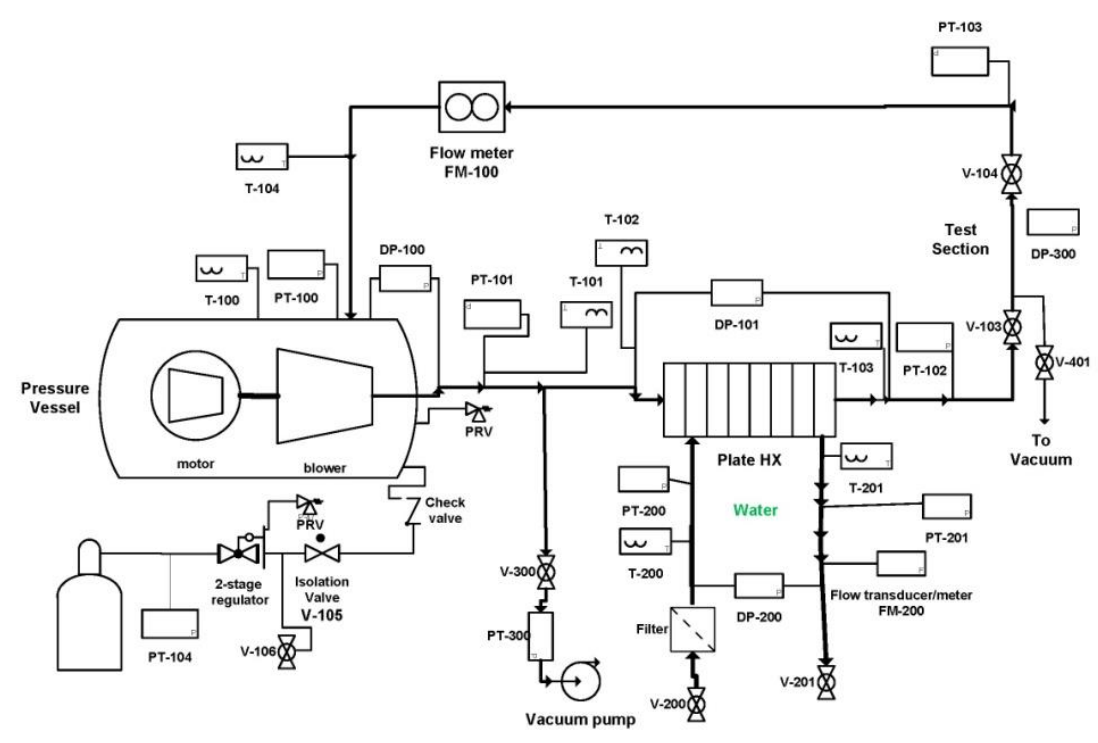

Figure 7. Flow loop Piping and Instrumentation Drawing.

\section{Blower Performance}

Blower performance measurement were taken to establish the mass flow rate as a function of the closed loop pressure drop. Pressure drop and flow rate were varied using a throttle valve. Measurement swere made at 4 motor rpm. The results are shown in Figure 8.

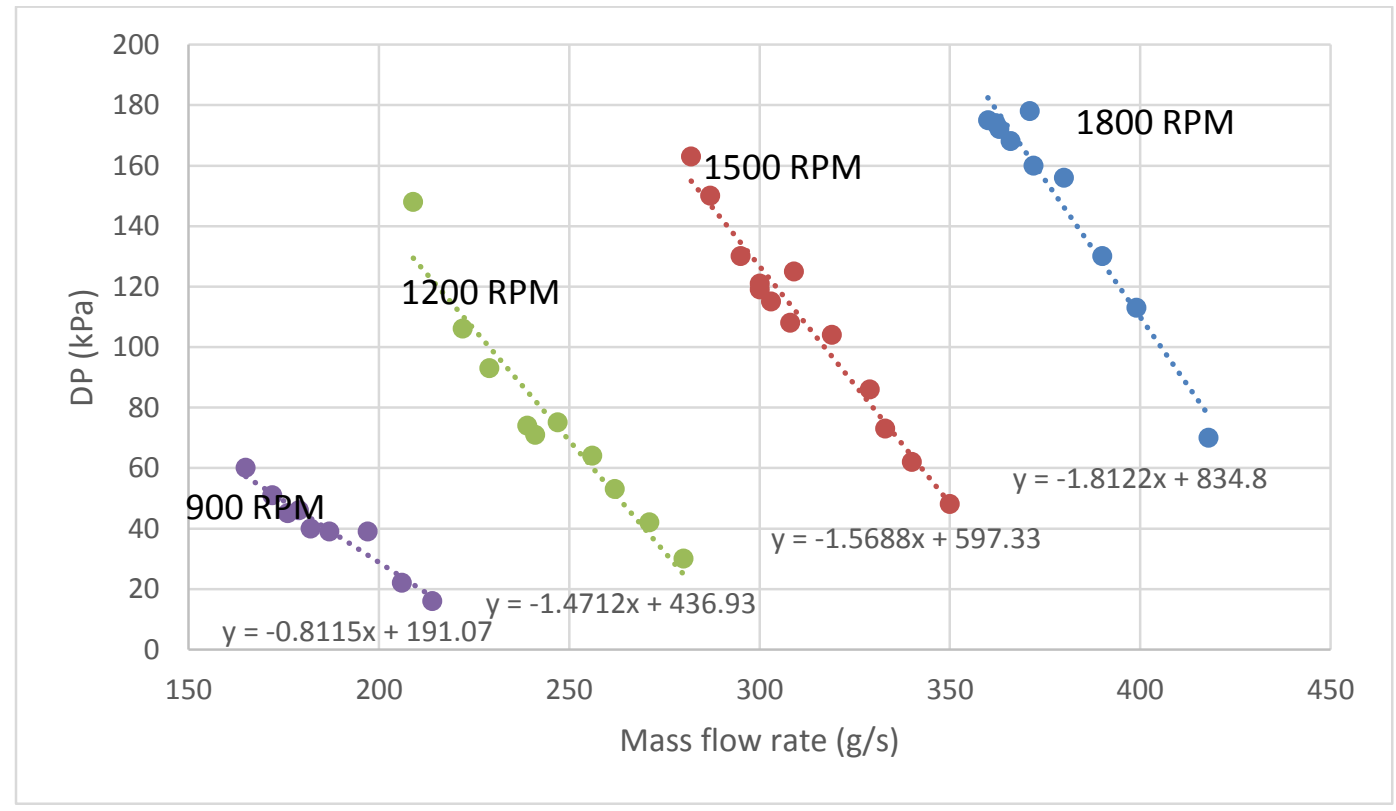

Figure 8. Blower performance curves. 
For operation in the facility, and therefore for most testing, the blower is intended to run at full speed, $1800 \mathrm{rpm}$. Figure 9 shows that performance curve reproduced from Figure 8, along with the vendor prediction for this inlet pressure, 26.7 bar. It is clear that the actual performance is better than the vendor would predict. For example, the blower can deliver the design point of $400 \mathrm{~g} / \mathrm{s}$ with $115 \mathrm{kPa}$ or flow resistance, while that flow rate can only be delivered when the pressure drop is lowered to $80 \mathrm{kPa}$. Stated another way, when the loop pressure drop is $115 \mathrm{kPa}$, the actual flow rate of $400 \mathrm{~g} / \mathrm{s}$ is about 20 $\mathrm{g} / \mathrm{s}$ higher than expected.

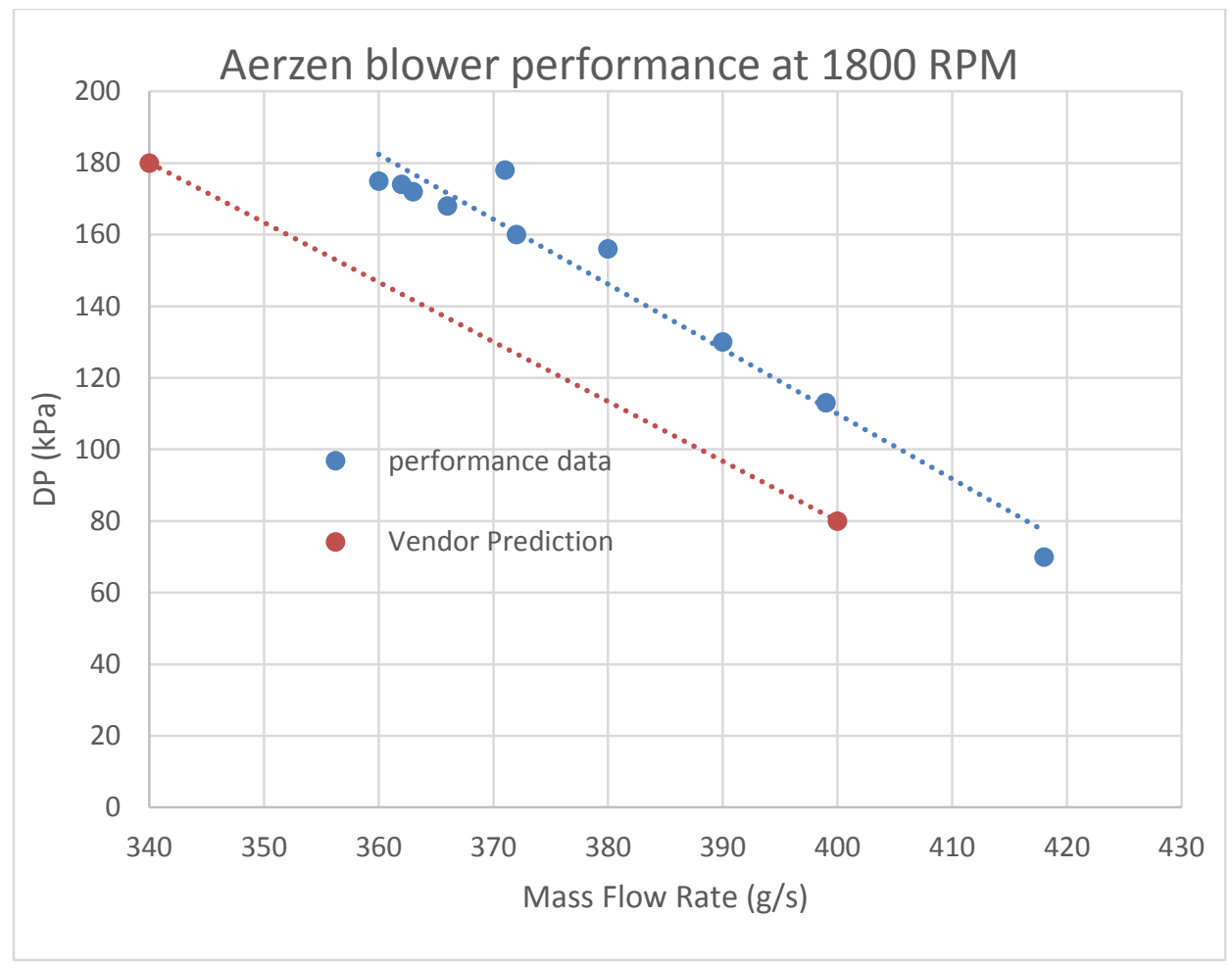

Figure 99. Measured performance compared with vendor prediction.

\section{Status and Conclusions}

The blower/motor/pressure vessel set-up is installed and ready. The first test section is straight pipe with a ball valve or globe valve for blower characterization. Final data acquisition software and hookups have been completed. Performance testing has been completed with favorable results. With the exception of a second heat exchanger to remove target heat, and a tritium removal slip stream, this loop is nearly identical to that envisioned for the Northstar production plant. 
Appendix A. Pressure Vessel Calculations for Blower/Motor Enclosure.

Cylindrical Shell

$\mathrm{t} \geq \mathrm{PR} /(2 \mathrm{SE}+0.4 \mathrm{P})$

$\mathrm{P}=400 \mathrm{psi}$

SA515-70 steel (or equivalent, $70 \mathrm{ksi}$ UTS or greater), $\mathrm{S}=20000 \mathrm{psi}$

$\mathrm{E}=0.6$, butt welds

$\mathrm{R}=14.625 "$

$t \geq 0.242^{\prime \prime}$

Sch 10 pipe, $t=0.375^{\prime \prime}$

Domed Elliptical Head

$\mathrm{t} \geq \mathrm{PD} /(2 \mathrm{SE}-0.2 \mathrm{P})$

$E=1$, no welds on head

$t \geq 0.293 "$

$\mathrm{t}=0.375^{\prime \prime}$

Unstayed Flat Head

$\mathrm{t} \geq \mathrm{d}^{*}$ sqrt $\left(\mathrm{CP} / \mathrm{SE}+1.9 \mathrm{Wh}_{\mathrm{G}} / \mathrm{SEd}^{3}\right)$

$\mathrm{C}=.3$ (from UG-34)

$\mathrm{W}=\mathrm{W}_{\mathrm{m} 1}=0.785 \mathrm{G}^{2} \mathrm{P}+2 \mathrm{~b} 3.14 \mathrm{GmP}$, bolt load

$\mathrm{h}_{\mathrm{g}}=$ distance from gasket center to bolt circle $=4$

$\mathrm{b}=$ gasket width $=2.5$

$\mathrm{G}=$ gasket $\mathrm{OD}-2 \mathrm{~b}=33.75-2 * 2.5=28.75$

$\mathrm{m}=$ gasket factor $=2.00($ App $\times 2)$

$W=620640$

$t \geq 3.63$

$t=3.63$

Pressure Rating of Instruments and Piping

Flow meter MAWP 500 psi

Heat exchanger MAWP 450 psi

Piping is sch 40 SA-53 carbon steel with allowable stress $S=16000$ psi.

Allowable pressure $P=S E t /(R+0.6 t)$ 
$E=$ weld allowance, taken as 0.5. Flange welds are slip on flanges welded both sides. Other weldments are small Swagelok fittings for pressure and temperature measurements, fillet welds.

Sch 40 pipe has $R=1.03^{\prime \prime}, t=0.155^{\prime \prime}$

Allowable $\mathrm{P}=1104$ psi.

Pressure stress calculations are for design guidance but the ultimate qualification is the pressure test. The vessel was factory tested and stamped. The piping, with instruments, was tested $1 / 22 / 14$, as per attached record. System design pressure is $400 \mathrm{psig}$, with pressure relief valve set at $400 \mathrm{psig}$. Pressure test was conducted at 530 psig, greater than the required $130 \%$ of MAWP. 